\title{
ReSearch of Influence of Pulse Width Converter Frequency ON CHARACTERISTICS OF THE DC ELECTRIC DRIVE
}

\author{
Iosiff Breido \& Yevgeniya Ussova
}
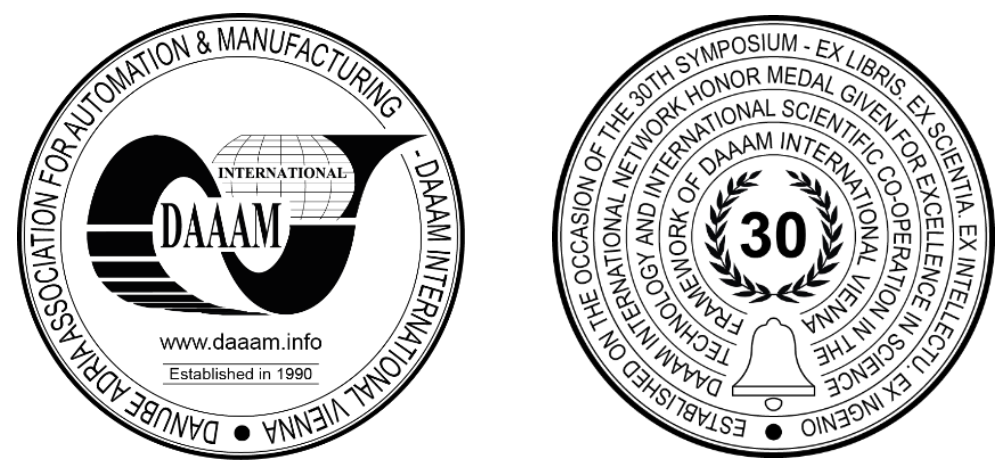

This Publication has to be referred as: Breido, I[osif] \& Ussova, Y[evgeniya] (2019). Research of Influence of Pulse Width Converter Frequency on Characteristics of the DC Electric Drive, Proceedings of the 30th DAAAM International Symposium, pp.0290-0297, B. Katalinic (Ed.), Published by DAAAM International, ISBN 978-3-902734-22-8, ISSN 1726-9679, Vienna, Austria

DOI: $10.2507 / 30$ th.daaam.proceedings.038

\begin{abstract}
At this stage of the development of Converter technology, one of the promising areas for improving the DC drive is the use of pulse-width modulation, built on the basis of IGBT-structures. The use of high-frequency pulse-width converters in conjunction with uncontrolled rectifiers in DC drives will significantly improve the static and dynamic characteristics of the drive by eliminating the modes of intermittent currents, delay and significant heating from pulsations. Currently, no studies of the DC electric drive with high-frequency pulse-width converters have been conducted and its rational parameters have not been determined. The purpose of this article is to study the DC drive with improved static and dynamic characteristics based on pulse width modulation.
\end{abstract}

Keywords: electric drive; direct current; IGBT; pulse-width modulation.

\section{Introduction}

The development of static semiconductor converters for controlled DC electric drive is directly related to the development of new devices and improvement of existing semiconductor ones. Currently, due to the development of industrial production of a new technical level power semiconductor devices and rapid development of computer technology, new opportunities appeared to improve static and dynamic characteristics of DC drives significantly. After IGBT transistors were invented, it became possible to design sufficiently compact and reliable power circuits of highpower pulse-width converters (100 kW and more) and, accordingly, electric drive systems based on them [6], [11].

The search for the optimal variant of the Converter for electric drives made us pay attention to the possibility of using scanning for optimal decision lead us to the next option: use semiconductor pulse converters powered by a three-phase supply through a rectifier and using pulse-frequency modulation or pulse-width modulation. Pulse width converters became implanted into drive mechanisms for Autonomous energy sources (on-road and construction vehicles, electric cars, etc.) [3], [8].

In modern pulse converters, the switching period is much less than the electromagnetic time constant of the motor, and current pulsations and, accordingly, losses in the armature winding are significantly reduced, since high-frequency semiconductor devices are used in them. However, as the frequency increases, losses in the switch and magnetic circuit of the motor increase, so the selection of the optimal switching frequency must be carried out taking into account specific 
parameters. Regulation with a constant frequency is more often used in existing electrical drives [4].

The use of high-frequency pulse-width converter together with uncontrolled rectifiers in AC networks will significantly improve the static and dynamic characteristics of direct current drive for eliminating the modes of intermittent currents, delays, and significant heating from ripple.

\section{Research of the DC electric drive characteristics}

In order to research the influence of the pulse-width converter frequency on the characteristics of drive "uncontrolled rectifier - high frequency pulse-width converter", developed on the basis of IGBT modules, laboratory stand was designed (on the basis of hardware-software complex of type 3 units SEM-4-0,55 SEF "Mechatronica - Pro") and experiments were carried out [1], [9].

The equivalent circuit of the power part of the developed electric drive is shown in Fig. 1.

The power voltage is supplied to the uncontrolled rectifier armature circuit. From the output of the uncontrolled rectifier through the capacity and the high frequency pulse-width converter (HF PWC) voltage is supplied to the motor armature circuit.

The singularity of this drive is the presence of the HF PWC and capacitive smoothing filter, which increase the speed of the drive, improve its energy characteristics and reduce the area of intermittent currents.

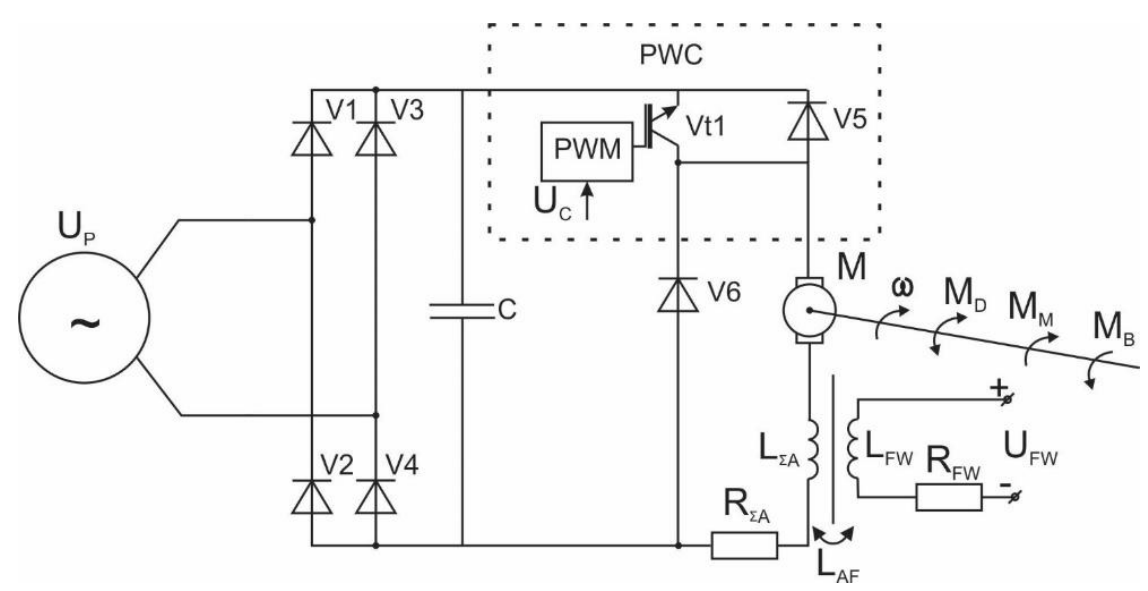

$\mathrm{U}_{\mathrm{P}}$ - power supply voltage, diodes (V1-V4) - single-phase uncontrolled rectifier C - capacity smoothing filter, PWC - pulse width converter, which consists of IGBT (VT1), shunt diode V5 and PWM (pulse width modulator), $\mathrm{U}_{\mathrm{C}}$ control voltage, M - DC motor, diode V6 - diode, shunt armature circuit of the motor $\mathrm{M}, \mathrm{L}_{\Sigma \mathrm{A}}$ - total inductance anchor circuit, $\mathrm{R}_{\Sigma \mathrm{A}}$ - the total resistance of the circuit of the armature, $\mathrm{L}_{\mathrm{AF}}-$ mutual inductance between armature circuit and circuit of the field winding, $\mathrm{L}_{\mathrm{FW}}$-inductance of the field winding, $\mathrm{R}_{\mathrm{FW}}-\mathrm{resistance}$ of the field winding $\mathrm{U}_{\mathrm{FW}}$ - the voltage supplied to the circuit of the field winding, $\omega$ - the angular velocity of the motor $\mathrm{M}, \mathrm{M}_{\mathrm{D}}-$ the dynamic torque of the electric motor $\mathrm{M}, \mathrm{M}_{\mathrm{M}}$-the moment of the electric motor $\mathrm{M}, \mathrm{M}_{\mathrm{B}}$ - the braking moment

Fig. 1. Equivalent circuit of DC drive

For the synthesis of automatic control system using MatLab implemented development of a mathematical model of the DC drive system "uncontrolled rectifier - HF PWC", its simulation model is shown in Fig. 2 [2], [5], [10].

The simulation model of the DC electric drive system "uncontrolled rectifier - HF PWC", presented in Fig. 2, was performed using the MATLAB.

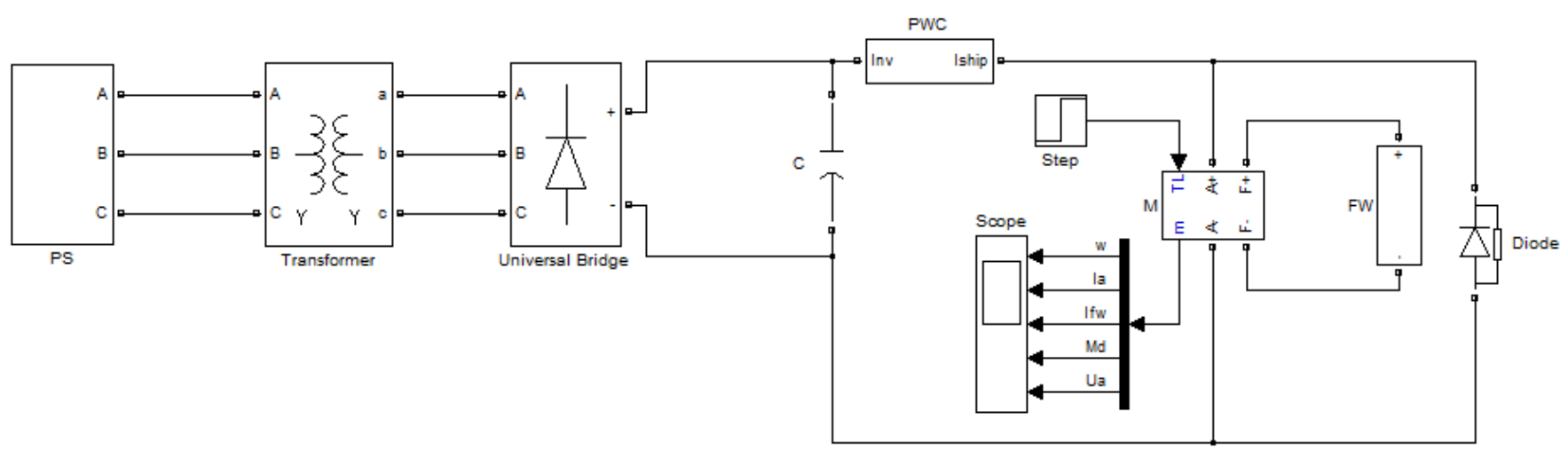

Fig. 2. Simulation model of DC electric drive 
The main functional blocks of the simulation model are:

- power source: three-phase, sinusoidal (PS);

- three phase transformer connection Y/Y (Transformer);

- uncontrolled rectifier: universal three-phase diode bridge (Bridge Universal);

- capacitive smoothing filter $(\mathrm{C})$;

- PWC: is a IGBT transistor, shunted by a diode and the control transistor (PWC);

- $\mathrm{DC}$ motor (M) with independent field winding (FW);

- Diode, shunt armature circuit of the motor (Diode);

- Scope that displays the dynamic characteristics of speed, current of the field winding and armature of the torque motor and the voltage in the anchor chain.

The processes ongoing in the motor are described by the system of equations (1) - (7) [7]:

$$
\begin{aligned}
& U_{O B}^{*}=i_{F W}^{*} \cdot \rho_{F W} \cdot\left(1+T_{F W}^{*} S\right) \\
& U_{A}^{*}=i_{A}^{*} \cdot \rho_{A} \cdot(1+s)+\Phi_{\Sigma}^{*} \cdot \omega^{*} \\
& \Phi_{\Sigma}^{*}=\Phi_{F W}^{*}+\Phi_{C W}^{*}-\Phi_{A R}^{*} \\
& \Phi_{F W}^{*}=f_{1}\left(i_{F W}^{*}\right) \\
& \Phi_{C W}^{*}=f_{2}\left(i_{A}^{*}\right) \\
& \Phi_{F R}^{*}=f_{3}\left(i_{A}^{*}\right) \\
& T_{M}^{*} S=\Phi_{\Sigma}^{*} \cdot i_{A}^{*}-M_{B}^{*}
\end{aligned}
$$

where

$s=\frac{d}{d t^{\prime \prime}}, t^{\prime}=\frac{t}{T_{A}}, U_{F W}^{*}=\frac{U_{F W}}{e_{R}}, i_{F W}^{*}=\frac{i_{F W}}{I_{R F W}}, \rho_{F W}=\frac{R_{F W} I_{R F W}}{\mathrm{e}_{R}}, T_{F W}^{*}=\frac{L_{F W} I_{R F W}}{\mathrm{e}_{R}} \cdot \frac{1}{\mathrm{~T}_{A}}, U_{A}^{*}=\frac{U_{A}}{e_{R}}, i_{A}^{*}=\frac{i_{A}}{I_{R A}}, \rho_{A}=\frac{R_{A \Sigma} I_{R A}}{\mathrm{e}_{R}}$, $\mathrm{T}_{A}=\frac{L_{A \Sigma} I_{R A}}{\mathrm{e}_{R}}, e^{*}=\frac{e}{\mathrm{e}_{R}}, \mathrm{e}_{R}=C \Phi_{R} \omega_{R}, \omega^{*}=\frac{\omega}{\omega_{R}}, \mathrm{M}_{B}^{*}=\frac{\mathrm{M}_{B}}{\mathrm{M}_{R}}, T_{M}^{*}=\frac{J \cdot \omega_{R}}{M_{R}} \cdot \frac{1}{T_{A}}, \Phi_{\Sigma}^{*}=\frac{\Phi_{\Sigma}}{\Phi_{R}} ; \Phi_{A R}^{*}=\frac{\Phi_{A R}}{\Phi_{R}} ; \Phi_{F W}^{*}=\frac{\Phi_{F W}}{\Phi_{R}}$, $\Phi_{C W}^{*}=\frac{\Phi_{C W}}{\Phi_{R}}$.

\begin{tabular}{|l|c|}
\hline \multicolumn{1}{|c|}{ Brand } & 4ПБ100S2 \\
\hline Power, $\mathrm{kW}$ (Continuous operation) & 0.75 \\
\hline The tension anchor $\left(\mathrm{U}_{\mathrm{A}}\right), \mathrm{V}$ & 220 \\
\hline Anchor circuit current, $\mathrm{A}$ & 4.5 \\
\hline Rated speed, $\mathrm{rpm}$ & 1500 \\
\hline Rated torque, $\mathrm{N} \cdot \mathrm{m}$ & 4.77 \\
\hline Field winding voltage, $\mathrm{V}$ & 220 \\
\hline
\end{tabular}

Table 1. Technical characteristics of DC machines

For building a simulation model, we used standard blocks of SPS Simulink libraries of MatLab.

To assess the adequacy of the electric drive simulation experiments were conducted in the most critical modes of operation:

- idling;

- nominal mode;

- mode with $\mathrm{U}_{\mathrm{A}}=0.5 \mathrm{U}_{\mathrm{AR}}$.

Experiment results from the modelling and real stand [9] are shown as following: voltage oscillogram of the idle mode on Fig. 3; same for the nominal mode on Fig. 4; same for the mode $U_{A}=0.5 U_{A R}$ on Fig. 5; current oscillogram for the mode $\mathrm{U}_{\mathrm{A}}=0.5 \mathrm{U}_{\mathrm{AR}}$ on Fig. 6. Experiments were conducted with pulse width modulation of $1 \mathrm{kHz}$. Result analysis is described below. 

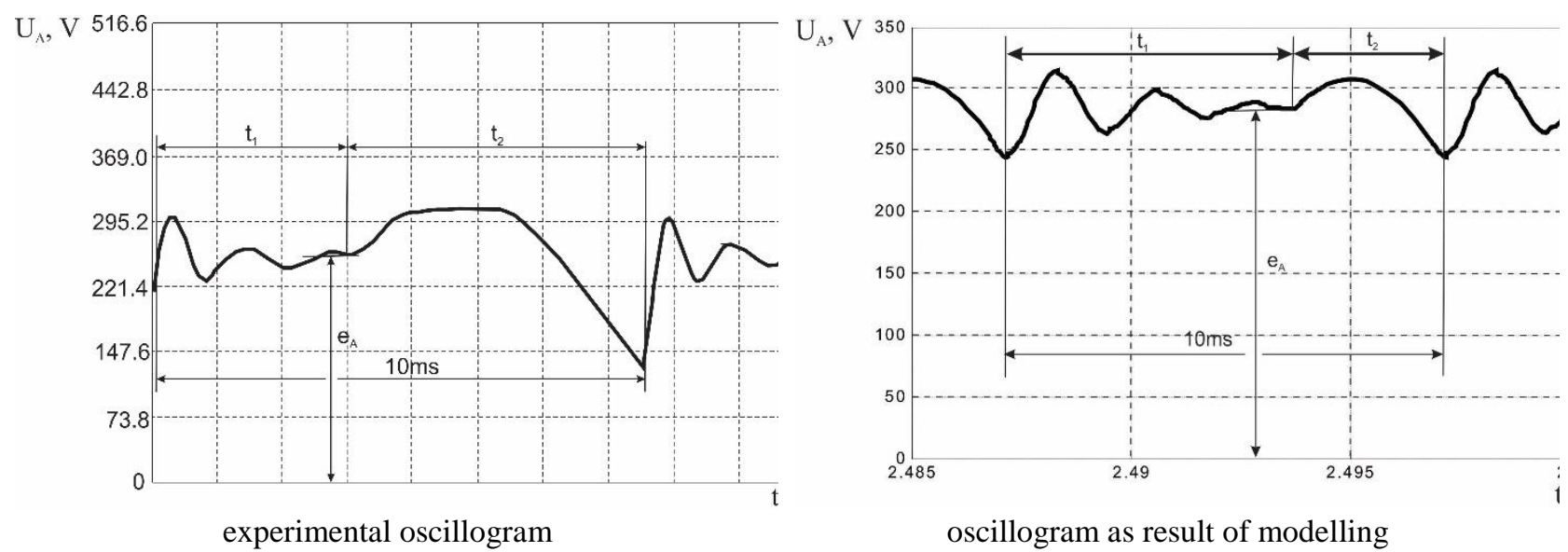

Fig. 3 - Anchor circuit voltage oscillogram of the idle mode

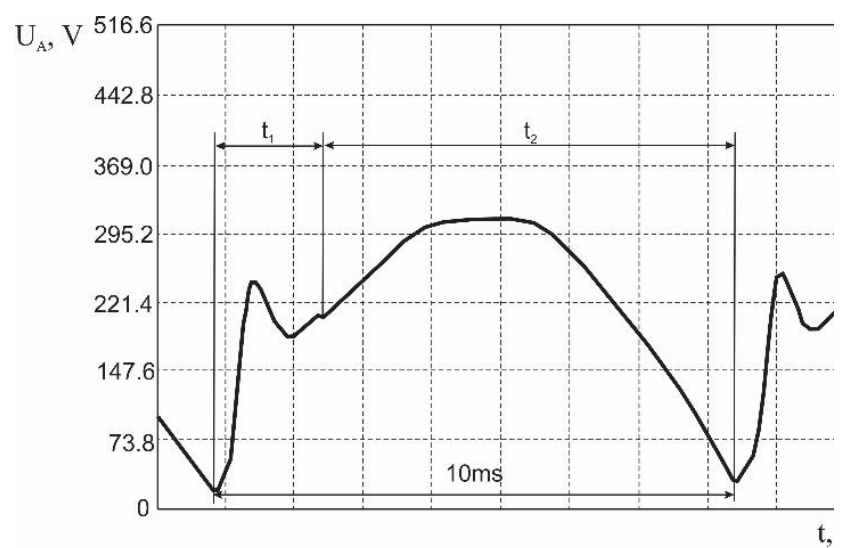

experimental oscillogram

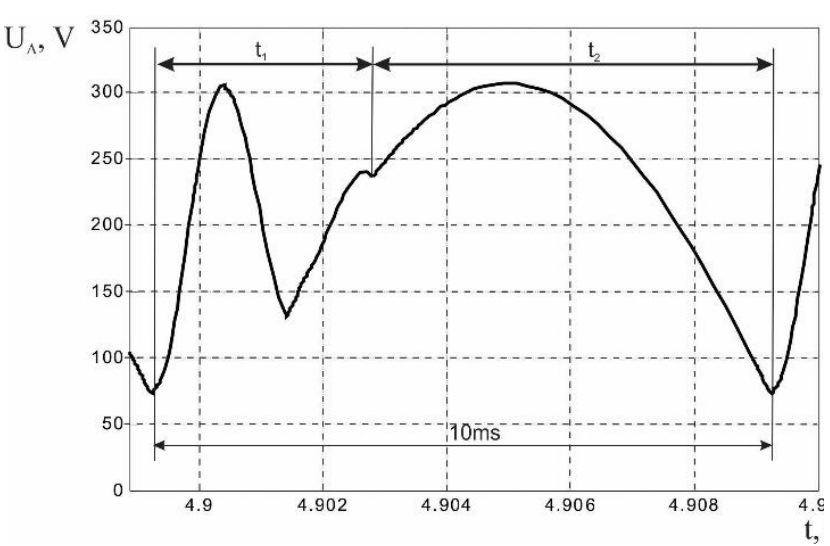

oscillogram as result of modelling

Fig. 4 - Anchor circuit voltage oscillogram of the nominal mode

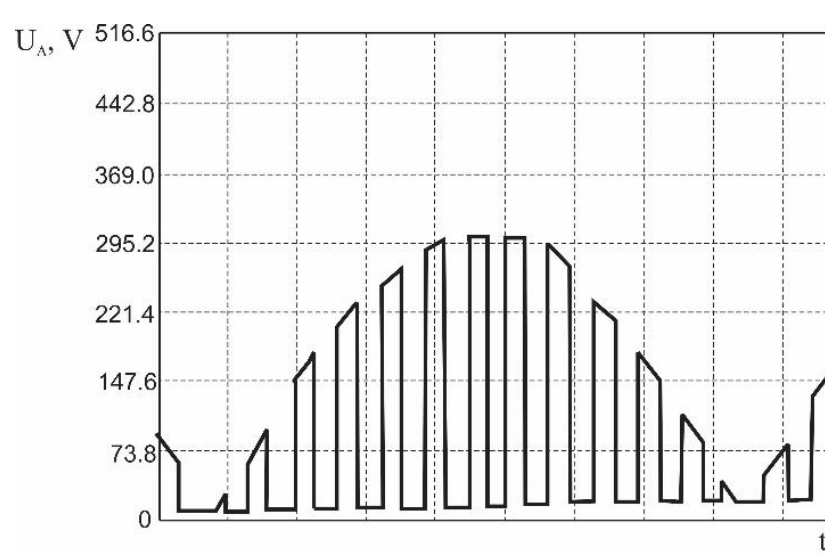

experimental oscillogram

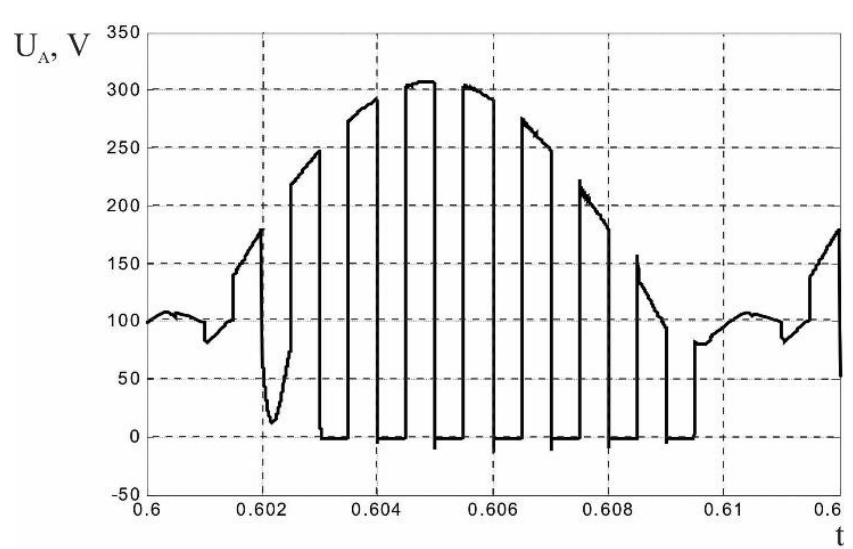

oscillogram as result of modelling

Fig. 5 - Anchor circuit voltage oscillogram of the mode $\mathrm{U}_{\mathrm{A}}=0.5 \mathrm{U}_{\mathrm{AR}}$ 


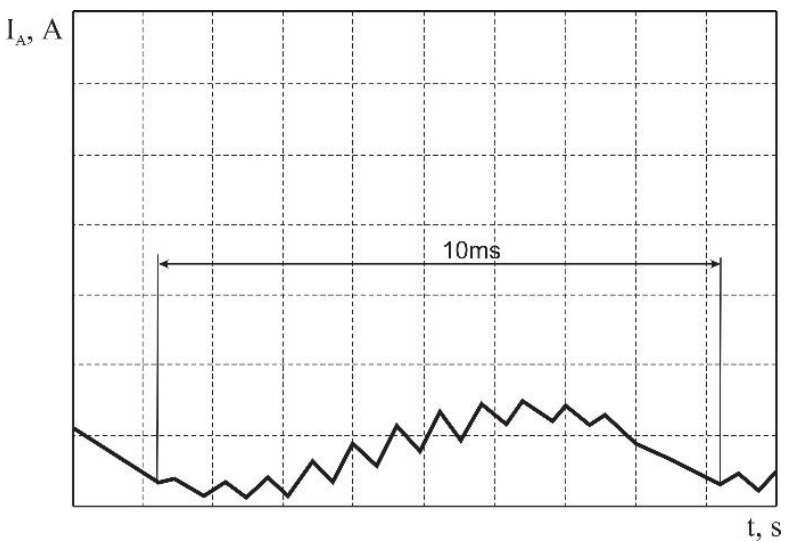

experimental oscillogram

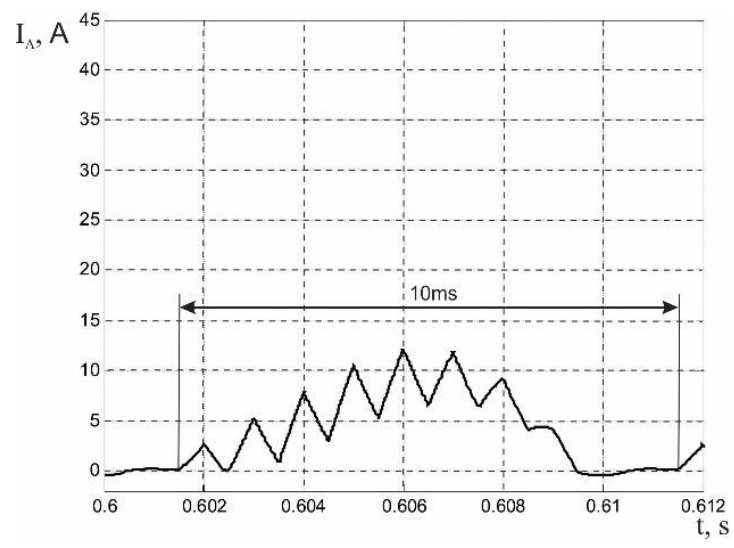

oscillogram as result of modelling

Fig. 6 - Anchor circuit current oscillogram of the mode $\mathrm{U}_{\mathrm{A}}=0.5 \mathrm{U}_{\mathrm{AR}}$ :

Intervals $t_{1}$ (Fig. 3-4) corresponds to zero current in anchor circuit. Oscillation occurs due to one pair of gates is closed and second pair is opened. Frequency of oscillation and attenuation rate are function of inductive and capacitive component of the anchor circuit and capacitance of the smoothing filter. Intervals $t_{2}$ (Fig. 3-4) are the feature of current flow through the anchor circuit. Common signature, amplitude and interval length of the oscillograms are the same for modelling and real case. Differences of those oscillograms are due to length of discharge of self-induction voltage $\left(t_{1}\right.$ intervals) and voltage surge in first third of $t_{1}$ interval. This is due to uncertainty of parameters of gates in dumping circuit set for modelling. But uncertainty level is less then $5 \%$.

On Fig. 3, experiment 1, last third of $t_{1}$ interval is self-induction voltage.

Oscillogram 3 and 4 (Fig. 5 and 6) states that current is uninterrupted in region of one pair of gates when power pack is closed and drive has load momentum on it. When one pair of gates is closing and another is opening current is interrupted. It needs to be noted, that interrupted current interval in current drive (with pulse width modulation of $1 \mathrm{kHz}$ ) is less then for the drives "Thyristor converter-motor" based on single phase full-wave rectifier.

Uncertainty level is less then $5 \%$ even on maximum load for these experiments.

Imitation model shown on Fig. 2 was used for testing dynamic and static characteristics for the drive system "uncontrolled rectifier - high frequency pulse-width converter". Experiments were conducted with different frequencies (1 to $40 \mathrm{kHz}$ ) of power pack commutation.

Power characteristics were formed with and without accounting loss in transformer (Fig. 7) using method of rootmean-square current. This approach allows us to estimate additional losses in the motor because it accounts for fluctuating component of the anchor circuit current and its relation to motor heating. Root-mean-square current was calculated for each value of frequency of power pack commutation during period.

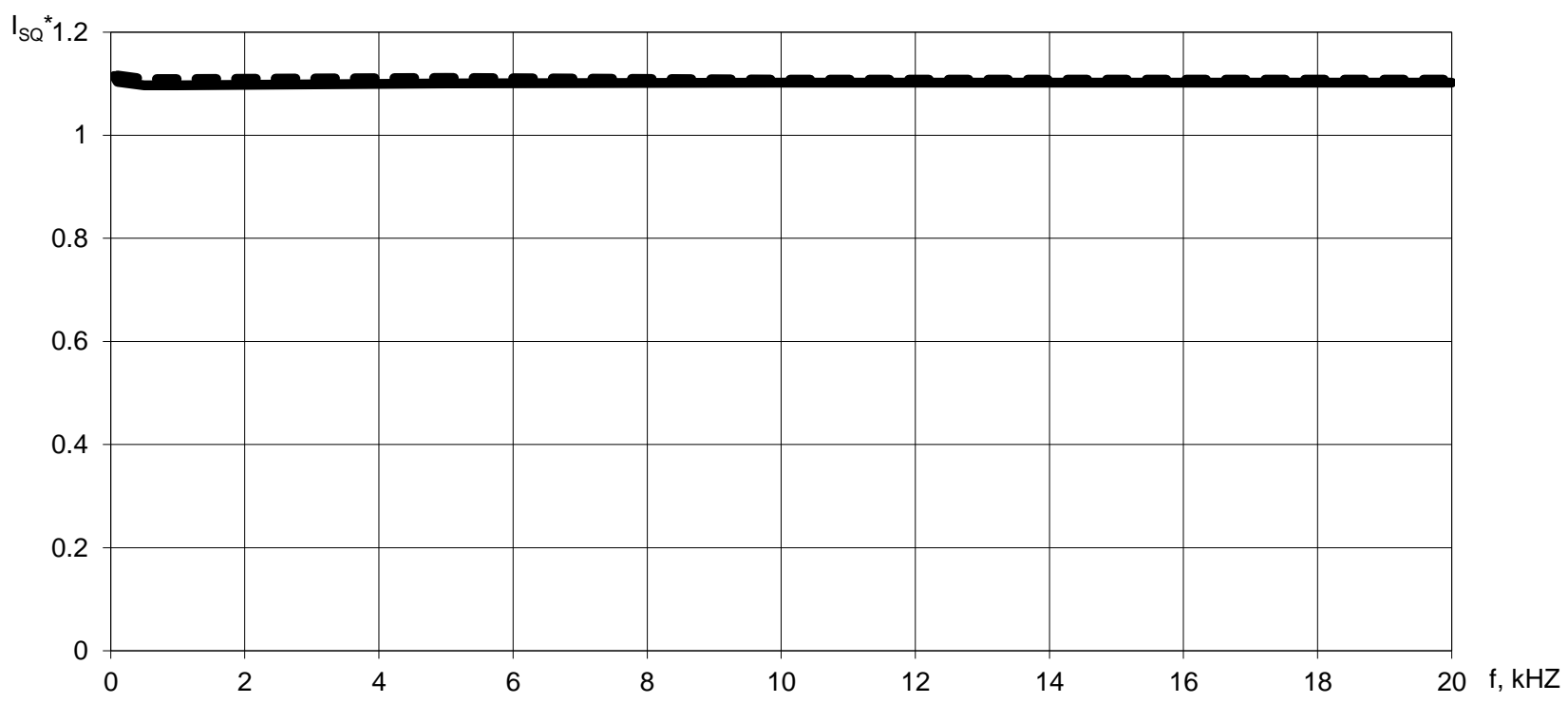

Power characteristic with accounting loss in transformer $-\boldsymbol{\bullet} \bullet$ Power characteristic without accounting loss in transformer $\mathrm{I}_{\mathrm{SQ}} *$ - root-mean-square current in drive's anchor circuit in relative units (r.u)., $\mathrm{f}$ - frequency of power pack commutation, $\mathrm{kHz}$

Fig. 7 - Power characteristics of drive $I_{\text {rmsq }} *=f(f)$ 
Root-mean-square Current $\left(\mathrm{I}_{\mathrm{SQ}}{ }^{*}\right.$ ) is trending down (starting from $500 \mathrm{~Hz}$ ) when PWM frequency increases in drive with accounting power loss in transformer.

On Fig. 8 Electromechanical characteristics are presented for the drive with accounting power loss in transformer. Coefficient of characteristics stiffness increasing by 8 percent when commutation frequency increases.

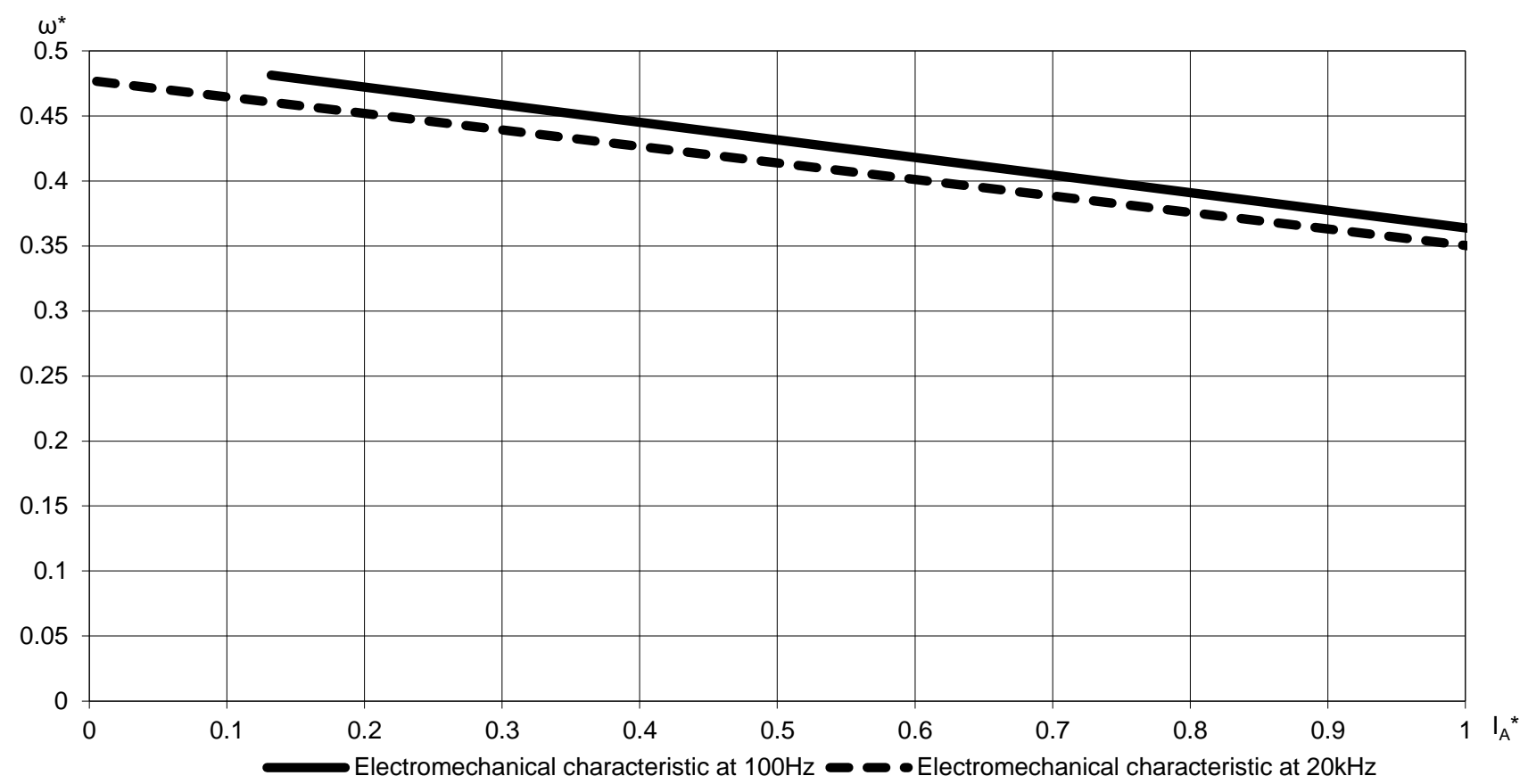

$\omega^{*}$ - drive's angular speed in r.u. $\mathrm{I}_{\mathrm{A}} *$ - drive's anchor circuit current in r.u.

Fig. 8 - Electromechanical characteristics $\omega^{*}=\mathrm{f}\left(\mathrm{I}_{\mathrm{A}} *\right)$

Experiments show that power loss of the electric motor is trending down and coefficient of characteristics stiffness is trending up when commutation frequency increases for power pack in drive "uncontrolled rectifier - high frequency pulse-width converter" type.

Research is intended to determine interrupted current zones for direct drive when following changes:

- Motor load from $5 \%$ to $120 \%$ of nominal value

- Pulse-width change from $0 \%$ to $100 \%$

- Pulse-width carrier frequency change $\left((2 \div 10) * 1 / \mathrm{T}_{\mathrm{A}}\right)\left(\mathrm{T}_{\mathrm{A}}-\mathrm{Time}\right.$ constant for anchor circuit of the motor);

- $\rho_{\mathrm{A}}$ value change $(0.05 \div 0.2)\left(\rho_{A}=\frac{r_{A} i_{A}}{e_{A}}\right.$, where $i_{A}$ - Current in anchor circuit, $e_{A}$ - self-induction in anchor circuit, $r_{A}$ - active resistance in anchor circuit).

Sequence of experiments was based on following:

1. Capacitor C (Fig. 2) was excluded from the model in order to determine more accurately interrupted current zones (without influence from capacitive smoothing filter)

2. Input voltage pulse ratio was changed from $10 \%$ to $100 \%$ for drives with $\rho_{Я}$ equal to $0.05,0.1,0.15,0.2$. During that mechanical load onto electric motor varied from $10 \%$ to $120 \%$ from nominal value.

3. While changing pulse-width parameters and load interrupted current points have been registered

Resulting diagrams are shown on Fig. 9.

On Fig. 9 diagrams, gray surface is limiting interrupted currents zone, i.e. everything below by vertical is where interrupted currents exists.

Diagrams 9a-d show interrupted currents zone for $\rho_{A}$, equal to $0.05,0.1,0.15,0.2 ; 9 \mathrm{e}-$ for all $\rho_{A}$; 9f - interrupted currents zone as function of commutation frequency of PWM T' for all $\rho_{A}$.

Equation [8] is the formula of conversion to real frequency from relative units for $\mathrm{T}^{\prime}$ (commutation interval).

$$
f=\frac{1}{T^{\prime} \cdot T_{Я}}
$$

Results of Fig. 9 diagrams analysis:

1. Interrupted currents zone increases when $\rho_{Я}$ decrease

2. There is maximum in region 50-60\% of PWM ratio on the graph of interrupted currents zone vs ratio of input voltage. This is due to transitional processes related to inductive component of anchor circuit of the motor;

3. Interrupted currents zone decreases when PWM frequency increase 
a

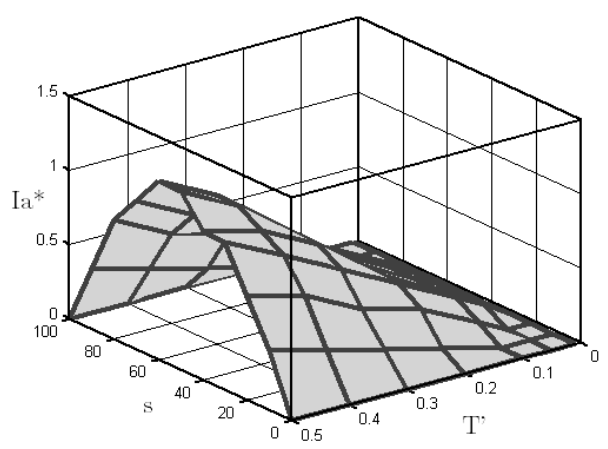

c

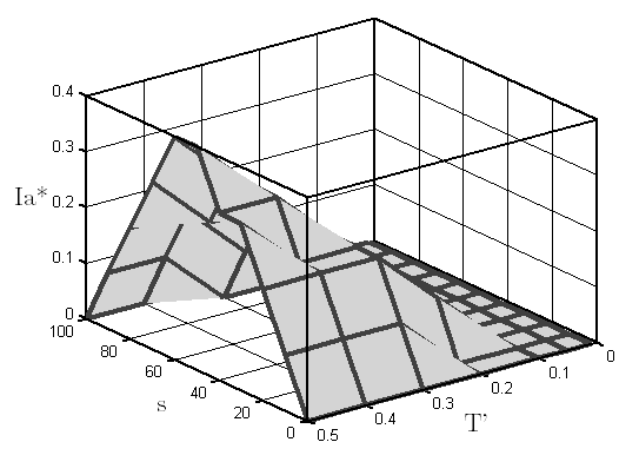

e

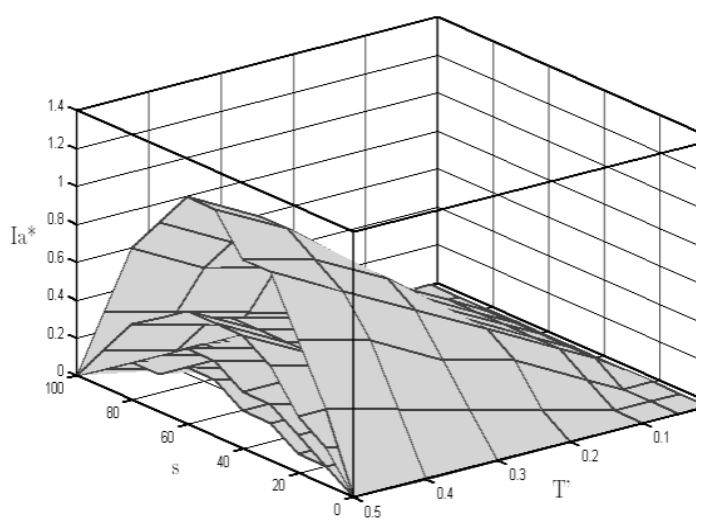

b

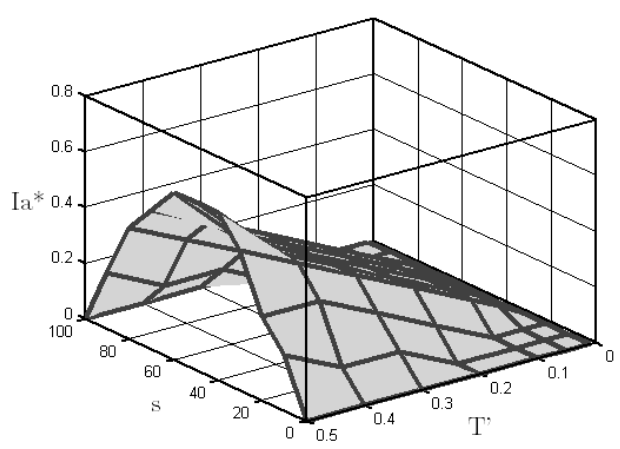

D

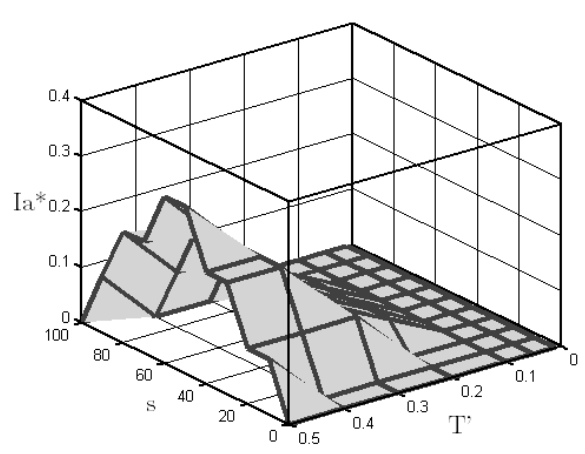

f

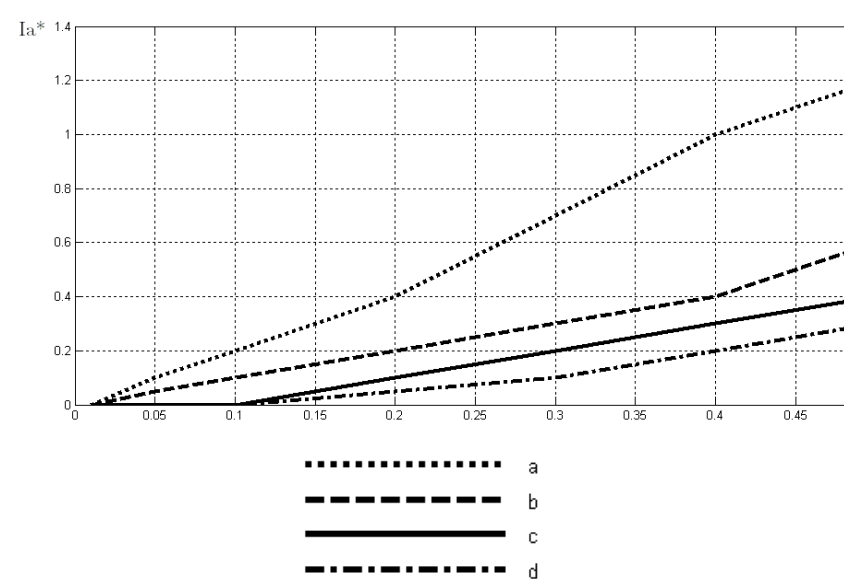

$\mathrm{I}_{\mathrm{A}} *$ - anchor circuit current in r.u., $\mathrm{s}$ - PWM ratio, $\mathrm{T}^{\prime}$ - commutation interval of PWM

Fig. 9 - Diagrams of interrupted current zones:

$\mathrm{a}-$ for $\rho_{A}=0.05, \mathrm{~b}$ - for $\rho_{A}=0.1, \mathrm{c}-$ for $\rho_{A}=0.15, \mathrm{~d}$ - for $\rho_{A}=0.2, \mathrm{e}, \mathrm{f}-$ for all $\rho_{A}$ 


\section{Conclusion}

Those Thyristor electric DC drives, which based on "controlled rectifier-electrical motor" principle, are widely used in all branches of industry. Well-known advantages of those drive systems: good controllability, a fairly wide range of speed control, the possibility of implementing various control modes, high reliability.

At the same time, the "controlled rectifier- electrical motor" system has a number of disadvantages. The most serious are the modes of intermittent currents due to the limited flutter rate of rectified voltage and its pulsed nature. The maximum flutter rate in the most common three-phase bridge rectification circuit is $300 \mathrm{~Hz}$, which limits the bandwidth of the drive, reducing its speed capability, and degrades the dynamic characteristics in controlling systems with feedbacks.

Additional heating of electric motors appears in the intermittent current modes, toughness of the mechanical characteristics decreases when working with small loads, the speed control range decreases down to the impossibility of obtaining bradykinetic (creeping) speeds.

Moreover, thyristor drives have poor electromagnetic compatibility with supply networks and appear as sources of powerful impulse noise.

There are opportunities to improve significantly static and dynamic characteristics of DC drives due to development of industrial production, rapid development of computer technology, reaching new technical level of power semiconductor - IGBT devices.

Next-generation option is to create an electric drive based on the system "Uncontrolled rectifier- high frequency pulsewidth converter". Increasing the switching frequency of the converter will increase response speed of the drive, improve its energy characteristics and reduce the zone of intermittent currents.

The Laboratory Rack was set up on the basis of the Type 3 hardware and software complex with the SEM-4-0.55 of SEF "Mechatronica-Pro". Experimental research was conducted in typical operating modes. Mathematical and simulation models were developed. As a result of theoretical and experimental studies identified:

- Influence of the PWC frequency on the static and energy characteristics of the drive;

- Determined the range of intermittent currents in the filling-factor functions and switching period functions,

- Extremums of the boundary values of intermittent currents.

The use of high-frequency pulse-width converters in conjunction with uncontrolled rectifiers in AC networks can significantly improve the static and dynamic characteristics of the DC semiconductor electric drive by eliminating: intermittent currents, delays and significant heating from current pulsations.

Research was limited to Laboratory Rack's electrical motor power capacity, which is obviously function of physical dimensions and availability. It might be scaled to the industrial capacities.

It is long-term plan to develop methods for calculating the smoothing filter at the input of the PWC, which provides minimal voltage pulsation and to select the type of modulation of the DC drive converter. It is also necessary to develop a closed-loop speed control system.

\section{References}

[1] Breido, I.V.; Sadvakasov, V.S. (2007) Direct current drive with pulse width modulation of increased frequency. Abstracts of the interuniversity regional student scientific conference. 19-20 April 2007 Part 1.Karaganda. Publishing house KSTU, 2007. 566c.

[2] Breido, I.; Feshin, B.; Kaverin, V. \& Em, G. (2010). Methodology of imitating modeling of the semiconductor electric drive of a direct current, Driving equipment, No.5 October 2010, Pages 44-48, ISSN: 2077-6411

[3] Breido, J. (2013). The state and prospects of development of the interconnected multi-motor semiconductor electric drives, DAAAM International Scientific Book 2013, Vol. 12, Pages 193-212, ISSN 1726-9687

[4] Breido I.; Kaverin V. \& Em G. (2018) The research of the adjustable electric drive of the direct current DAAAM International Scientific Book 2018 Vol. 17, p 211-226, ISSN 1726-9687

[5] Corcau, J. I. \& Dinca, L. (2015) Numerical model and experimental tests for DC to DC boost converter, DAAAM International Scientific Book 2015, Vol. 14, Pages 067-086, ISSN 1726-9687.

[6] Górecki, P.; Górecki, K.; Zarębski, J. (2017) Modelling the temperature influence on dc characteristics of the IGBT, Microelectronics Reliability, Vol. 79, December 2017, Pages 96-103, ISSN 0026-2714.

[7] Kaverin, V.V. (2000) Research and development systems controlled braking controlled drives continuous mining machines: dissertation work. Karaganda: KSTU, 2000. 127c.

[8] Malafeev, S.I. \& Malafeev, S.S. (2018) Dynamic loading of electric machines during testing, DAAAM International Scientific Book 2018, Vol. 17, Pages 325-330, ISSN 1726-9687.

[9] SEF “Mechatronica-Pro". Training stand type 3 unit SEM-4-0,55. User manual. Available from: http://mechatronicapro.com.

[10] Takakuwa, S. (2018) Integration of management and simulation for manufacturing systems, DAAAM International Scientific Book 2018, Vol. 17, Pages 273-284, ISSN 1726-9687.

[11] Zhou, L.; Wu, J.; Sun, P.; Du, X. (2014). Junction temperature management of IGBT module in power electronic converters, Microelectronics Reliability, Vol. 54, Issue 12, December 2014, Pages 2788-2795, ISSN 0026-2714 